STUDIA ROSSICA POSNANIENSIA, vol. XLII: 2017, pp. 115-126. ISSN 0081-6884.

Adam Mickiewicz University Press, Poznań

\title{
КОГНИТИВНАЯ СЕМАНТИКА И НАРРАТИВНЫЕ ФУНКЦИИ ПАРЕНТЕЗЫ КАЖЕТСЯ В РАЗНЫХ КОНТЕКСТАХ ХУДОЖЕСТВЕННОГО ДИСКУРСА
}

\author{
THE COGNITIVE SEMANTICS AND NARRATIVE FUNCTIONS \\ OF THE PARENTHESIS KAЖETCЯ IN DIFFERENT CONTEXTS \\ OF FICTIONAL DISCOURSE
}

\author{
ЕЛЕНА ЧЕРНЦОВА
}

\begin{abstract}
This article analyzes the cognitive semantics of the parenthesis кажется, as well as its functions in developing a fictional narrative strategy. The analysis shows that the parenthesis кажется does not have its own conceptual value and it is functionally related to the subject's reflection on cognitive activity, whose contents are predetermined by various perspectives of the context. The semantics and narrative functions of the parenthesis кажется are identified within such parameters as 'communicative logic of the cognitively active subject', 'subjective structure of context', along with a 'communicative register' - 'reproductive' or 'informative' - and a 'narrative strategy'.
\end{abstract}

Елена Чернцова, Харьковский национальный университет им. В. Н. Каразина, Харьков - Украина, e.v.cherntsova@yandex.ru

В предыдущих публикациях автора была показана когнитивная семантика и функции парентезы кажется в диалогических контекстах обыденного дискурса ${ }^{1}$, а также нарративных контекстах разных жанров - обыденного рассказа, бытового письма; автобиографических жанров (мемуаров, записок, дневника); публицистического эссе; научно-публицистических жанров².

Исследование дискурсивно обусловленных значений базируется на анализе, выявляющем смысловое соответствие словесного выражения целям и установкам говорящего. Дискурсивный анализ в этом случае базируется на таких параметрах: 'дискурсивный тип контекста'; 'нарративная стратегия'; 'коммуникативный регистр' (репродуктивный - информативный - генеритивный - волюнтивный - реактив-

1 Е. В. Ч е р н ц о в а, Дискурсивная семантика парентезы „кажется”, „Вісник Харківського національного університету. Сер.: Філологія" 2012, № 1014, с. 91-98.

2 Е. В.Ч е р н ц о в а, Дискурсивные проекции парентезы „кажется" в жанрах нарратива, [в:] Слов'янський збірник (збірник наукових працъь), Видавничий дім Дмитра Бураго, вип. 17, ч. 2, Київ 2012, с. 535-540. 
ный)'; 'субъект когнитивной деятельности'; 'субъектная структура контекста'.

Параметр 'дискурсивный тип контекста' актуализирует специфику референции текста (в данном случае художественного), предопределенную характером связанного с ним мира (в данном случае фикционального). Специфический характер фикционального мира задают воображение и память - основные категории художественного сознания, они же предопределяют способ сообщения о нем. Так, логика художественного дискурса формирует различные речевые планы повествования, в которых реализуются позиции рассказчика (повествование от 1-го лица), нарратора (повествование от 3-го лица), персонажа. Эти планы фиксируются термином 'субъектная структура контекста' и позволяют различать дискурс персонажа и дискурс рассказчика или нарратора. Для выявления особенностей функционирования парентезы кажется, ее роли в синтаксическом оформлении 'коммуникативной позиции говорящего', которая традиционно описывается в категориях прямой, косвенной, свободной косвенной речи, будем последовательно отвечать на вопрос: кто является субъектом когнитивного акта, маркируемого парентезой кажется, - нарратор, рассказчик или персонаж.

В решении поставленной задачи важна взаимосвязь между когнитивным значением парентезы кажется и художественной нарративной стратегией, осмысляемой в контексте параметра 'коммуникативный регистр ${ }^{3}$. Коммуникативный регистр понимается лингвистами как определенный тип отражения действительности, обусловленный точкой зрения говорящего, его пространственно-временной позицией, запечатленной в тексте. В контексте задач исследования вводится различие репродуктивного и информативного характера коммуникативного регистра. Репродуктивный регистр представляет субъекта, который находится в локусе описываемого им события, в силу чего он констатирует лишь только то, что видит, слышит или чувствует непосредственно. Информативный регистр имплицирует субъекта, который не просто описывает то, что видит, но интерпретирует наблюдаемую ситуацию: осмысляет, оценивает ее с позиций собственного понимания.

Дискурсивный анализ может выявить когнитивную значимость слова в построении той или иной нарративной стратегии, связанной с репродуктивным или информативным регистром. Для того чтобы дифференцировать высказывание с парентезой кажется и более широкий контекст, частью которого является это высказывание, примем

${ }^{3}$ Г. А. 3 о л о т о в а, Н. К. О н и п е н к о, М. Ю. С и д о р о в а, Коммуникативная грамматика русского языка, под общ. ред. Г. А. Золотовой, Наука, Москва 2004, c. 29-35. 
следующие условные обозначения: высказывание с парентезой - 'контекст парентезы'; более широкое дискурсивное окружение - 'внешний контекст'. Анализ значимости парентезы в разных типах художественного контекста, представленных в дискурсивном материале Национального корпуса 4 русского языка, позволяет различать частные типы контекстов.

\section{1. Диалогический контекст прямой речи персонажа}

1.1. Внешний репродуктивный контекст (первого типа). Парентеза кажется принадлежит дискурсу персонажа, который выступает 'субъектом когнитивной деятельности'. Начнем с диалогического контекста репродуктивного регистра, в котором персонаж представлен как участник ситуации, опирающийся на данные своего наблюдения, ср. (1): - Вот этот, - кричала ему барышня, становясь на колени перед могучим телом бородача дворника, - кажется, дышит, господин офицер, дайте ему воды (П. Н. Краснов, От Двуглавого Орла к красному знамени). В репродуктивном контексте обретает значимость синхронность времени наблюдения и времени события. Субъект-наблюдатель выдвигает предположение о состоянии наблюдаемого лица. Парентеза кажется в таком случае отражает интерпретационный ментальный акт субъекта-наблюдателя, который осознает принципиальную невозможность истинного суждения о физическом состоянии наблюдаемого лица по ряду причин, в частности субъект может осознавать свою некомпетентность в таких вопросах. Иллокуция интерпретационного диалогического речевого акта, выраженная парентезой кажется, может быть определена следующим образом: 'говорящий высказывает свою версию происходящего и приглашает адресата к его верификации: поправь меня, если я ошибаюсь'. Парентезой кажется маркируется актуальный (для моделируемого в диалогическом контексте момента времени) рефлексивный акт субъекта-наблюдателя.

Двойственность семантики кажется состоит в том, что рефлексия по поводу наблюдаемого как вид когнитивной деятельности отражает не только репродуктивную ('описываю то, что вижу'), но и информативную коммуникативную установку субъекта речи ('предлагаю свой вариант понимания происходящего, осознавая, что могу ошибаться'). Несмотря на внешний репродуктивный контекст, функцию парентезы кажется можно интерпретировать как функцию маркера информативного и волюнтивного речевого акта персонажа. Подобную функцию выполняет парентеза в ситуации обыденного диалога о наблюдаемом собеседниками положении дел. Функциональная нагрузка парентезы

\footnotetext{
${ }^{4}$ См. электронный ресурс: http://www.ruscorpora.ru/
} 
в художественном диалогическом контексте увеличивается, в частности за счет указания на особенности 'речевого портрета персонажа'.

1.2. Внешний информативный контекст (второго типа). В этом случае реплика с парентезой кажется принадлежит персонажу, строящему свое предположение не на непосредственном наблюдении, а на определенных фоновых знаниях, ср. (2): - А он всё-таки здесь! - Не понимаю... - пожал плечами студент Конякин. - Мы с Гагаровым друзья, и он, если бы вернулся, первым долгом известил бы меня. - Он, кажется, скрывается, - постукивая носком ботинка о ковёр, сообщила Серафима Петровна. - За ним следят. Последняя фрраза, очевидно, была сказана просто так, чтобы прекратить скользкий разговор о Гагарове. Но студент Конякин забеспокоился. (А. Т. Аверченко, Ложъ). Рассмотрим коммуникативную структуру диалога персонажей. Реплика - Он, кажется, скрывается - выполняет в структуре диалога двойную роль: высказывания-реакции на предшествующий речевой акт собеседника и высказывания-сообщения об обсуждаемом предмете речи, которое задает проспекцию дискурса. В контексте задач нашего исследования важна роль парентезы в формировании особой иллокуции сообщения - Он, кажется, скрыBaemcя, в котором представлена интерпретация субъектом-персонажем мотивов поведения другого персонажа. В таком контексте парентеза выполняет функцию маркера процесса становления мысли персонажа, его рефлексии: персонаж представляется как субъект, который находится в состоянии активного мыслительного процесса. Отметим еще раз, что субъект дискурса изображается как дистанцированный в пространстве и времени, но имеющий некоторые представления об объекте осмысления.

1.3. В внешнем информативном контексте (третьего типа) представлен рассказчик, вспоминающий о деталях прошлого события, а парентеза кажется маркирует рефлексию над соответствующей когнитивной деятельностью - 'если я правильно помню', 'если мне не изменяет память'. Ср. (3): Я тогда ухаживал за одной местной, ничего была женщина, как же её звали? Кажется, Настя. -Нина, -подсказал Скворияов. - Не путай, Нина - это в другой раз. А на этот раз была Настя, я теперь твёрдо вспомнил (И. Грекова, На испытаниях). Нарративная стратегия, разворачивающая процесс воспоминания персонажа-рассказчика, строится из фрагментов разного типа - автодиалога (как же её звали? Кажется, Настя) и собственно диалога (Нина, - подсказал Скворцов. - Не путай, Нина - это в другой раз). В таком контексте кажется маркирует установку рассказчика на восстановление в памяти забытой информации.

Таким образом, контекст парентезы может быть связан с внешним репродуктивным контекстом и с внешним информативным контекстом. Различия между возникающими контекстными значениями па- 
рентезы можно объяснить особенностями коммуникативной логики 'субъекта когнитивной деятельности': в ситуации непосредственного наблюдения субъект восприятия осмысляет полученное впечатление и его рефлексивный акт направлен на понимание или объяснение увиденного: субъект интерпретирует физические или ментальные состояния наблюдаемого лица или возможные причины наблюдаемого события (контекст № 1). В процессе осмысления тех или иных ситуаций интерпретационный акт субъекта опирается на впечатления, полученные в прошлом, фоновые знания о предмете мысли, которые часто обобщаются, систематизируются в процессе обдумывания (контекст № 2). В процессе воспоминания интерпретация субъекта базируется на припоминании всей той информации, которая содержится в памяти говорящего (контекст № 3). В этом случае рефлексивный акт направлен на процесс восстановления информации в памяти.

Коммуникативная логика субъекта-наблюдателя обусловливает характер субъектной структуры внешнего репродуктивного контекста, которая включает субъекта-наблюдателя, субъекта речи и субъекта рефлексии над полученным впечатлением. Эти три позиции субъекта могут совпадать в персонаже (контексте № 1). Коммуникативная логика субъекта-носителя знания реализуется в виде иной субъектной структуры: субъект фоновых знаний, субъект рефлексии и субъект речи. Логика репродуктивного регистра задает в контексте значение парентезы, отражающее актуальную (во временном значении термина) рефлексию субъекта-наблюдателя, а логика информативного регистра формирует либо значение 'рефлексивный интерпретационный акт субъекта-носителя знаний', либо 'рефлексивный акт субъекта, который вспоминает нечто'.

Реализация того или иного варианта контекстного значения парентезы кажется зависит от параметров внешнего контекста. Если в контексте эксплицитно фиксируется значение 'ретроспективный взгляд субъекта', формируемое лексическими средствами (помнить, вспоминать и др.), то парентеза становится знаком 'рефлексии над воспоминанием' - 'если я правильно помню', 'если мне не изменяет память'.

Таким образом, главная особенность парентезы состоит в том, что она не имеет собственного понятийного значения: кажется функционально связана с рефлексией субъекта над когнитивной деятельностью, содержание которой обусловлено различными планами контекста.

Поскольку парентеза кажется может отражать актуальный рефлексивный акт субъекта-наблюдателя, а рефлексия как тип когнитивной деятельности (как и интерпретация, объяснение) концептуально связана с коммуникативной установкой информативного регистра, то парентеза получает дополнительную функциональную нагрузку - мар- 
кирует смену коммуникативного регистра с репродуктивного на информативный, что отражает движение авторской мысли в тексте.

\section{2. Нарративный контекст косвенной речи}

Как показывает дискурсивный анализ, контекстное значение парентезы кажется координируется с коммуникативной логикой субъекта дискурса ('субъект когнитивной деятельности'). Так, в обыденном дискурсе коммуникативная логика говорящего предопределяется различными обстоятельствами, в частности субъект может не обладать абсолютным знанием о событии по ряду причин: например, говорящий может забыть некоторые подробности той ситуации, свидетелем которой он был. В таком случае рефлексивный акт будет направлен на восстановление в памяти всех деталей произошедшего. Характер рефлексии ('если мне не изменяет память') говорящего фиксируется ментальной рамкой мне кажется, парентезой кажется.

В художественном дискурсе коммуникативная логика иная: нарратор моделируется как субъект-носитель абсолютного знания о событиях художественного мира, при этом свое присутствие в тексте нарратор чаще всего не выражает эксплицитной ментальной рамкой мне кажется, однако парентеза кажется часто встречается в дискурсе нарратора в функции, которую уточним далее. Рассмотрим роль парентезы кажется в организации нарративной стратегии в различных типах контекста.

2.1. Внешний информативный контекст (четвертого типа) со значением 'ретроспективный взгляд нарратора', в котором парентеза маркирует рефлексию нарратора над актом воспоминания.

Начнем с контекстов, в которых нарратор запечатлен как субъект, в целом владеющий всей информацией о персонаже и событиях его жизни (а не субъект-наблюдатель), но как будто бы забывший некоторые подробности, ср. (4): ПоступиВши в Красную Армию еще в 1918 году, он многократно успел доказать свою преданность общему делу, был, кажется, ранен, командиров всех знал лично, понимал их верно, ладил с ними по-товарищески, и они его пюбили и уважали - „свой" был, словом, человек (Д. А. Фурманов, Чапаеb). В контексте представляется фрагмент биографии персонажа. Зная о судьбе персонажа все, нарратор, тем не менее, выбирает языковые средства, эксплицирующие актуальную мыслительную деятельность, что привносит в контекст мемуарный характер. Парентезы кажется, словом выступают маркерами когнитивного стиля нарратора - неавторитарного, некатегоричного размышления, включающего рефлексию (кажется, ранен) и собственные выводы („свой” был, словом, человек). Ср. также следующий контекст (5): Тотчас силы удвоились: испитой врангелевеи, некогда ротмистр ея императорского величества 
гусарского полка, Варшавского, кажется, и в доску нашенский квадратный полковник-танкист (Ю. Давыдов, Синие тюльпаны).

В следующих информативных контекстах с парентезой нарратор также моделируется как субъект, который, сообщая нечто о прошлых событиях, „запамятовал” фамилию одного из героев своего рассказа, ср. (6): Анна Францевна де Фужере, пятидесятилетняя почтенная и очень деловая дама, три комнаты из пяти сдавала жильцам: одному, фрамилия которого была, кажется, Беломут, и другому - с утраченной фрамилией (М. А. Булгаков, Мастер и Маргарита); ср. похожий контекст (7): Кто-то из лётчиков, кажется, Молчанов, ответил, ито есть плохие люди среди всех наций (В. Гроссман, Жизнь и судьба); далее речь идет о номере смеси, который „восстанавливает в своей памяти” нарратор, ср. (8): Тайное знание: покупать следовало смесь под определенным номером, кажется, 36, поскольку она содержала не только грузинский чайный лист, но и изъестную долю индийского (Б. Кенжеев, Из Книги счастья).

2.2. Внешний репродуктивный контекст (пятого типа). Если контекст отражает ретроспективный взгляд нарратора на события художественного мира и строится из фрагментов разных регистровых блоков: внешнего репродуктивного и информативного - то нарративная функция парентезы усложняется, ср. (9): Плясали свои и приглашённые гости, московские и приезжие, писатель Иоганн из Кронштадта, какой-то Витя Куфтик из Ростова, кажется, режиссёр, с лиловым лишаём во всю щёку, плясали виднейшие представители поэтического подраздела МАССОЛИТа, то есть Павианов, Богохульский, Сладкий, Шпичкин и Адельфина Буздяк, плясали неизвестной профрессии молодые люди $b$ стрижке боксом, с подбитыми ватой плечами, плясал какой-то очень пожилой с бородой, в которой застряло пёрышко зелёного лука, плясала с ним пожилая, доедаемая малокровием девушка в оранжевом шёлковом измятом платьице (М. А. Булгаков, Мастер и Маргарита). Контекст в целом описывает внешние, наблюдаемые извне действия персонажей, отнесенные в план прошлого: Плясали свои и приглатённые гости, московские и приезжие, писатель Иоганн из Кронштадта; внешние, наблюдаемые извне приметы персонажей - ...с лиловым лишаём во всю щёку...; ...молодые ююди в стрижке боксом, с подбитыми ватой плечами; очень пожилой с бородой, $b$ которой застряло пёрышко зелёного лука...; ...доедаемая малокровием девушка $b$ оранжевом шёлковом измятом платьище. Репродуктивно-описательная нарративная стратегия отражает точку зрения нарратора-наблюдателя. Сообщение же, формируемое парентезой (какой-то Витя Куфтик из Ростова, кажется, режиссёр), отражает информативный регистр, парентеза маркирует когнитивный акт субъекта (нарратора), связанный с припоминанием профессии „наблюдаемого” персонажа. Фрагменты разных регистров выполняют определенные функции в построении 
художественного текста: предложения репродуктивного регистра служат констатации происходящего (наблюдаемого) в художественном мире, а предложения информативного регистра выражают мысли, реакции нарратора на наблюдаемое событие в целом либо его участников. Сочетание фрагментов разных регистров создает движение мысли в тексте - от описания увиденного к его объяснению, осмыслению. Нарративная функция парентезы кажется усложняется во внешнем репродуктивном контексте косвенной речи: сам контекст имплицирует позицию субъекта-экспериенцера - участника события, а парентеза указывает на нарратора, маркирует его когнитивный акт - 'припоминание некоторой информации о персонаже'. В таком контексте нарратор моделируется и как субъект-наблюдатель, и как субъект когнитивной деятельности.

2.3. Внешний репродуктивный контекст (шестого типа), в котором парентеза маркирует когнитивный акт интерпретации „видимого” и "слышимого” нарратором (без значения "рефлексия над воспоминанием'). Большинство контекстов такого типа строится из блоков разных коммуникативных регистров - репродуктивного и информативного. Так, например, в следующем контексте нарратор моделируется как находящийся в том же локусе, что и его персонажи, нарратор как будто бы видит все, что происходит, и слышит все, о чем говорят персонажи. К средствам, обнаруживающим локус нарратора, относятся глаголы, выражающие прямое восприятие субъектом-наблюдателем описываемых действий персонажа - Мудряк... подмигивал и прищелкивал пальиами... Ср. (10): Мудряк, кажется, понимал, что мелет чушь, и потому подмигивал и прищелкивал пальцами; обращался к Милию Алексеевичу на "ты", но это было не внове Милию Алексеевич: ююди, вовсе с ним незнакомые, чаще всего говорили ему "ты", и он не одергивал, а только как бы немножко конфузился за них „тыкающих" (Ю. Давыдов, Синие тюльпаны). Парентеза кажется принадлежит дискурсу нарратора, маркирует его когнитивный акт, направленный на объяснение причины увиденного: почему персонаж ведет себя таким образом. Парентеза фиксирует рефлексивный акт - 'колебания субъекта между стремлением вынести истинное суждение и осознанием принципиальной невозможности истинного суждения о содержании чужих мыслей'. Парентеза выполняет функцию 'переключателя' коммуникативных регистров - с репродуктивного на информативный, что позволяет, во-первых, усложнить субъектную структуру контекста - нарратор моделируется в нем как субъект-наблюдатель и одновременно как субъект рефлексивного акта; во-вторых, передать движение мысли в тексте - от внутренней мотивации поступка персонажа к описанию его поведения; от причины к следствию. 
В контексте репродуктивного регистра парентеза кажется отражает коммуникативную логику субъекта (нарратора-наблюдателя) - установку понять и объяснить читателю „видимое” и „слышимое” нарратором. Нарративная функция парентезы усложняется за счет импликаций - 'нарратор наблюдает за описываемым событием', 'владеет полной информацией о персонажах, хочет объяснить читателю внутреннюю мотивацию поступков персонажей, раскрыть содержание их мыслей'.

\section{3. Нарративный контекст свободной косвенной речи}

3.1. Внешний репродуктивный контекст (седьмого типа). В нарративных контекстах свободной косвенной речи ${ }^{5}$ парентеза выполняет функцию маркера рефлексивного акта персонажа, включенного в виде трансформированной цитаты в дискурс нарратора. Ср. (11): Неспешно подойдя к машине, шофёр сказал, ито полетел, кажется, кардан, пассажиры его спешат, не подвезёт ли он их до Москвы (А. Азольский, Лопушок). Чтобы показать нарративную функцию парентезы, трансформируем синтаксическую форму контекста свободной косвенной речи в прямую речь персонажа и слова автора и сравним два контекста: Неспешно подойдя к машине, шофеёр сказал - Полетел, кажется, кардан. Мои пассажиры спешат. Не подвезете ли Вы их до Москвы? Сопоставление двух контекстов - авторского и трансформированного нами - показывает, что с синтаксической точки зрения весь авторский контекст представляет собою косвенную речь, кроме парентезы. Парентеза кажется - знак интерпретационного акта, субъектом которого выступает персонаж, а значит, парентеза цитируется нарратором. Парентеза становится индикатором синтаксической техники свободной косвенной речи. В таком контексте парентеза кажется выполняет функцию маркера пересечения двух дискурсов, посредством которого имплицируется их связь, а значит, задается пространственно-временная позиция нарратора-наблюдателя описываемой ситуации. Нарратор моделируется в контексте как находящийся в том же локусе, что и его персонажи, нарратор как будто „слышит” то, что говорит персонаж, и пересказывает его слова читателю.

Если нарративный контекст сообщает о пересказе нарратором слов персонажа, содержит предикативную конструкцию типа - он сказал, что...; она говорит, что..., то парентеза имплицирует значение - 'пространственно-временные позиции нарратора-наблюдателя и персонажа, моделируемые в тексте, синхронны'. В такой многоголосой кон-

\footnotetext{
${ }^{5}$ Свободной косвенной речью называется синтаксическая техника, смешивающая формы косвенной и прямой речи.
} 
струкции содержится два субъекта диктума, два их референта и три предикации: одна - от речи персонажа и две - от авторской. Таким образом, парентеза открывает субъектную позицию для когнитивного (рефлексивного) акта персонажа в дискурсе нарратора. Субъектная структура контекста усложняется: в нем два субъекта речи - персонаж и нарратор, а также представлен субъект рефлексии - персонаж. Нарративная стратегия при этом описывает состояние сознания персонажа, строится как совмещающая две точки зрения: „изнутри” сознания персонажа и оценивающая позиция „извне”, принадлежащая нарратору-наблюдателю.

3.2. Внешний контекст свободной косвенной речи (восьмого типа). Нарративный контекст пересказа речевого акта воспоминания близок к предыдущему контексту свободной косвенной речи. Ср.: (12): Что они потом говорили и где были, Корнилов помнит очень плохо. Кажется, вдвоём они провожали Марью Григорьевну. Кажется, потом Марья Григорьевна проводила их (Ю. О. Домбровский, Факультет ненужных вещей). Нарративная стратегия использует точку зрения персонажа: нарратор воссоздает в своем дискурсе речевой акт персонажа, направленный на то, чтобы вспомнить произошедшее с ним, персонажем, событие. Представления об устойчивых причинно-следственных связях позволяют интерпретировать контекст следующим образом: в контексте имплицируется нарратор в позиции наблюдателя или даже участника прошлого разговора с персонажем: нарратор „слышит” сказанное персонажем.

Синтаксическое построение контекста таково: первое сложное предложение с придаточными изъяснительного типа представляет собою контекст косвенной речи - Что они потом говорили и где были, Корниnob помнит очень плохо; но второе и третье предложения - контекст свободной косвенной речи, так как содержит парентезу кажется, принадлежащую дискурсу персонажа и маркирующую его рефлексивный акт - 'насколько я помню', 'если меня не подводит память'. Поскольку парентеза кажется заимствуется нарратором из дискурса персонажа, то в контексте формируется прагматическая импликатура: пространственно-временные позиции персонажа и нарратора синхронны, персонаж „сообщил" нарратору релевантную для повествования информацию.

Проанализированный материал позволяет сделать такие выводы:

1. Парентеза кажется не имеет собственного понятийного значения, функционально связана с рефлексией субъекта над когнитивной деятельностью, содержание которой обусловлено различными планами контекста. Контекстное значение парентезы кажется задается коммуникативной логикой 'субъекта когнитивной деятельности', скоординировано с 'коммуникативным регистром', 'субъектной структурой' внешнего контекста. 
2. Коммуникативный регистр организован как когнитивный гештальт-сценарий, центром которого выступает 'субъект когнитивной деятельности'. В контексте репродуктивного регистра представлены три позиции субъекта - субъект-наблюдатель, субъект речи и субъект рефлексии (кажется). В 'субъектной структуре' контекста информативного регистра вместо позиции субъекта наблюдения имплицируется позиция субъекта-носителя знания, обладающего полной информацией о событии.

3. Когнитивную семантику парентезы кажется, связанную с рефлексивным актом субъекта, можно представить в виде трех когнитивных сценариев:

- Субъект-наблюдатель рефлектирует над увиденным (в момент восприятия): его интенции направлены на то, чтобы различить то, что он видит, либо убедиться в 'истинности / обманчивости' первого впечатления, которое часто предполагает последующую интерпретацию мотива поступка человека или причины наблюдаемого события. Диалогический рефлексивный акт субъекта ориентирован на адресата - 'поправь меня, если я ошибаюсь'.

- Субъект-носитель знания выдвигает свою интерпретацию происходящего в художественном мире, маркируя парентезой рефлексивный акт, который отражает установку на поиск 'адекватного' суждения, при этом субъект допускает, что может ошибаться. Рефлексивный акт, как правило, носит реактивный характер и представлен в диалоге персонажей.

- Субъект-носитель знания воспоминает некоторые подробности, его рефлексивный акт направлен на процесс восстановления информации в памяти - 'если мне не изменяет память'.

В художественных контекстах разного типа выявленные сценарии представляются либо в чистом виде, либо совмещаются по принципу палимпсеста: 'субъект рефлектирует над впечатлением, полученным в прошлом'.

4. Сравнение контекстов диалогической речи персонажей (1-3) с контекстами косвенной речи нарратора (4-10) показывает различия в функционировании парентезы, которые объясняются коммуникативной логикой 'субъекта когнитивной деятельности'. Когнитивной основой рефлексивного акта нарратора выступает либо моделируемая в тексте ситуация 'наблюдения' за событием художественного мира (первый когнитивный сценарий), либо 'воспоминание' (третий сценарий). В контекстах косвенной речи не представлен второй когнитивный сценарий, в котором не содержится ни апелляции к 'наблюдению', ни к 'воспоминанию' (второй когнитивный сценарий реализуется исключительно в контексте диалогического типа). 
5. По мере усложнения субъектной структуры нарративного художественного контекста функциональная нагрузка парентезы кажется возрастает:

- в контекстах информативной биографической стратегии парентеза маркирует рефлексивный акт нарратора, направленный на восстановление в памяти некоторой информации; такая стратегия не опирается, как правило, на репродукцию зрительных впечатлений и образов (внешний контекст четвертого типа);

- в контекстах нарративной стратегии, совмещающей различные коммуникативные установки, парентеза актуализирует позицию нарратора, 'переключает' регистр с репродуктивного на информативный, в результате чего в контексте создается импликация: 'нарратор вспоминает нечто о „наблюдаемом” персонаже' (внешний контекст пятого типа);

- в контекстах репродуктивной стратегии (внешний контекст шестого типа) парентеза кажется отражает коммуникативную логику субъекта-наблюдателя, обусловленную установкой объяснить читателю „видимое” и „слышимое" нарратором;

- в рамках стратегии пересказа нарратором речи персонажа парентеза играет двойную роль: в дискурсе персонажа сигнализирует о его рефлексивном акте - 'интерпретации' или 'припоминании' (внешний контекст седьмого и восьмого типа), а в дискурсе нарратора имплицирует единую пространственно-временную локализованность нарратора и персонажа.

\section{Библиография}

3 о л о т о в а Г. А., О н и п е н к о Н. К., С и д о р о в а М. Ю., Коммуникативная грамматика русского языка, под общ. ред. Г. А. Золотовой, Наука, Москва 2004, c. 29-35.

Ч е р н ц о в а Е. В., Дискурсивная семантика парентезы „кажется”, „Вісник Харківського національного університету. Сер.: Філологія" 2012, № 1014, с. 91-98.

Ч е р н ц о в а Е. В., Дискурсивные проекции парентезы „кажется” В жанрах нарратива, [в:] Слов'янський збірник (збірник наукових праци), Видавничий дім Дмитра Бураго, вип. 17, ч. 2, Київ 2012, с. 535-540.

Электронный ресурс: http://www.ruscorpora.ru/ 